\title{
Influence of an Interaction between Lithium Salts and a Functional Polymorphism in SLC1A2 on the History of Illness in Bipolar Disorder
}

\author{
Sara Dallaspezia $\cdot$ Sara Poletti $\cdot$ Cristina Lorenzi \\ Adele Pirovano $\cdot$ Cristina Colombo • \\ Francesco Benedetti
}

Published online: 25 September 2012

(C) Springer International Publishing Switzerland 2012

\begin{abstract}
Background Bipolar disorder (BD) is a recurrent and disabling illness, characterized by periods of depression and mania. The history of the illness differs widely between patients, with episode frequency emerging as a strong predictor of poor illness outcome. Lithium salts are the first-choice long-term mood-stabilizing therapy, but not all patients respond equally to the treatment. Evidence suggests that alterations in glutamatergic systems may contribute to the pathophysiology of depression. Moreover, glutamate signaling is involved in brain development and synaptic plasticity, both of which are modified in individuals affected by BD, and has been implicated in the etiology of the disorder. The inactivation of glutamate is handled by a series of molecular glutamate transporters (excitatory amino acid transporters [EAATs]), among which EAAT2/SLC1A2 is responsible for up to $95 \%$ of extracellular glutamate clearance. A functional singlenucleotide polymorphism at $-181 \mathrm{bp}$ from the transcription start site of the SLC1A2 gene has been described. This T-to-G (DNA forward strand) polymorphism, commonly known as $S L C 1 A 2-181 \mathrm{~A}>\mathrm{C}$, affects transporter expression, with the variant $\mathrm{G}$ allele inducing a $30 \%$ reduction in promoter activity compared with the $\mathrm{T}$ allele.

Objective The aims of the study were to investigate if factors affecting glutamate function, such as SLC1A2
\end{abstract}

S. Dallaspezia $(\bowtie) \cdot$ S. Poletti · C. Lorenzi · A. Pirovano ·

C. Colombo $\cdot$ F. Benedetti

Department of Clinical Neurosciences,

Istituto Scientifico Ospedale San Raffaele,

San Raffaele Turro, Via Stamira d'Ancona 20,

Milan, Italy

e-mail: dallaspezia.sara@hsr.it
$-181 \mathrm{~A}>\mathrm{C}$ ( $\mathrm{rs} 4354668)$, could affect recurrence of illness in $\mathrm{BD}$, and if they interact with lithium salt treatment. Methods We performed an observational study in our university hospital in Milan. We enrolled 110 subjects (76 females, 34 males) affected by BD type I. The exclusion criteria were other diagnoses on Axis I, mental retardation on Axis II, a history of epilepsy, and major medical and neurologic disorders. Fifty-four patients had been treated with lithium salts for more than 6 months. Patients were genotyped for SLC1A2 $-181 \mathrm{~A}>\mathrm{C}$ by polymerase chain reaction-restriction fragment length polymorphism, and the influence of genotype on BD episode recurrence rates, and the interaction between the single nucleotide polymorphism and lithium treatment, were analyzed.

Results The SLC1A2 -181A $>$ C genotype significantly influenced the total recurrence of episodes, with $\mathrm{T} / \mathrm{T}$ homozygotes showing a significantly lower frequency of episodes $(\mathrm{F}=3.26 ; \quad p=0.042)$, and an interaction between lithium treatment and genotype $(\mathrm{F}=3.77$; $p=0.026)$ was found to influence the history of the illness.

Conclusion According to our results, the glutamatergic system could be hypothesized to exert some influence on the history of illness in BD. The SLC1A2 functional polymorphism was shown to significantly influence the total episode recurrence rate, with wild-type $\mathrm{T}$ homozygotes presenting the lowest number of episodes, $\mathrm{G}$ homozygotes reporting the highest number, and heterozygotes showing an intermediate phenotype. We confirmed the efficacy of lithium treatment in reducing the recurrence of illness in $\mathrm{BD}$, and we found an interaction between lithium treatment and the SLC1A2 $-181 \mathrm{~A}>\mathrm{C}$ genotype, confirming previous studies reporting an interaction between lithium salts and the glutamatergic system. 


\section{Introduction}

Bipolar disorder (BD) is a recurrent and disabling illness, characterized by periods of depression and mania. Among bipolar patients, the episode frequency can range from once in a lifetime to many per year, with over $90 \%$ of patients experiencing more than one affective episode during their lifetime [1]. Episode frequency emerges as a strong predictor of poor illness outcome [2, 3]. The clinical features, phenomena, and evolution of the disorder differ between men and women, especially the course of the illness, with manic episodes being more common in men and depressive episodes occurring more frequently in women [4].

Lithium salts are the first-choice long-term mood-stabilizing therapy for $\mathrm{BD}$, with proven efficacy in preventing relapse of both mania and depression, but not all patients respond equally to lithium therapy. Clinical predictors account for less than half of the variance, and there is evidence suggesting that genetic factors play a substantial role in influencing the response $[5,6]$.

Glutamate is the principal excitatory neurotransmitter in the central nervous system, with glutamatergic neurons being prominently represented in the cerebral cortex and limbic regions of the brain. Accumulation of excess extracellular glutamate and subsequent overstimulation of glutamatergic receptors increase the production of reactive and excitotoxic oxygen/nitrogen species, which induce oxidative stress, leading to neuronal death [7]. The inactivation of glutamate is handled by a series of molecular glutamate transporters (excitatory amino acid transporters [EAATs]), which are membrane-bound pumps that closely resemble ion channels. These transporters play the important role of regulating concentrations of glutamate in the extracellular space, maintaining it at low physiologic levels that promote biologic function without promoting toxicity [8]. Five human EAATs have been cloned; among them, EAAT2 is responsible for up to $95 \%$ of extracellular glutamate clearance [9]. Although EAAT2 is expressed primarily on astrocytes, it has also been found in neurons and oligodendrocytes [10]. Impairment of glutamate uptake by dysfunction or reduced expression of EAAT2 has been implicated in the pathogenesis of various neurodegenerative diseases, such as Alzheimer's disease, Huntington's disease, and amyotrophic lateral sclerosis [7].

The gene encoding EAAT2 in humans is SLC1A2 [solute carrier family 1 (glial high affinity glutamate transporter), member 2], located on chromosome 11p13-12 [11]. Mallolas and colleagues [12] described a T-to-G (DNA forward strand) functional polymorphism at $-181 \mathrm{bp}$ from the transcription start site of the SLC1A2 gene, which is commonly known as $-181 \mathrm{~A}>\mathrm{C}$. The mutation abolishes a putative regulatory site for activator protein- 2 and creates a new binding site for the transcription repressor factor GC- binding factor 2, resulting in less transporter expression and with the $\mathrm{C}$ allele inducing a $30 \%$ reduction in promoter activity compared with the A allele.

The mutant genotype has been associated with an increase in blood glutamate levels and with a worse outcome of human stroke [12]. It has also been associated with higher glutamate plasma levels during the course of a relapse in multiple sclerosis [13]. Moreover, in a recent study, the polymorphism was shown to affect the personality trait of reward dependence in healthy Japanese subjects [14].

Evidence suggests that alterations in glutamatergic systems may contribute to the pathophysiology of depression [15], with elevated levels of the neurotransmitter being observed in the cerebral cortex of depressed subjects [16]. Glutamate signaling is involved in brain development and synaptic plasticity, both of which are modified in individuals affected by BD and have been implicated in the etiology of the disorder [17]. An elevated brain glutamate/glutamine (Glx) level and reduced levels of $N$-methyl-D-aspartate (NMDA) receptor subunits have been reported in postmortem brain tissue from BD patients [18]. Moreover, a recent study demonstrated significantly altered expression of transporters of glutamate in postmortem frontal cortex tissue from BD patients where EAAT2 protein and mRNA levels were found to be decreased [10]. Riluzole, which inhibits glutamate release, was shown to be able to promote an antidepressant response in patients with treatment-resistant BD $[19,20]$. Moreover, ketamine-a noncompetitive, high-affinity NMDA receptor antagonist which, in vitro, increases the glutamatergic neuron firing rate and presynaptic glutamate release [21] - shows robust and rapid antidepressant effects [22]. Different single proton magnetic resonance spectroscopy studies have found that Glx levels are consistently elevated in both adult patients [23, 24] and pediatric patients [25] affected by BD and, in a previous study, we found that a treatment-induced decrease in the Glx to creatine ratio in $\mathrm{BD}$ patients was paralleled by the antidepressant response [26].

Moreover, genetic polymorphisms involved in the glutamatergic system, such as single nucleotide polymorphisms in glutamate receptor metabotropic 3, ionotropic glutamate receptor $N$-methyl D-aspartate $2 \mathrm{~B}$, and $\mathrm{D}$-amino-acid oxidase activator, have been found to influence the history of illness in BD [27].

The main aims of this study were to investigate if SLC1A2 $-181 \mathrm{~A}>\mathrm{C}$ (rs4354668), which is known to influence glutamate function, could affect recurrence of illness in $\mathrm{BD}$, and if this effect interacts with lithium salt treatment.

\section{Methods}

The study enrolled 110 Caucasian subjects (76 females, 34 males) consecutively referred to our university hospital 
from January 2009 to December 2011 for BD type I (according to the DSM-IV criteria; diagnosed using the Structured Clinical Interview [SCID]). The exclusion criteria were other diagnoses on Axis I, mental retardation on Axis II, a history of epilepsy, and major medical and neurologic disorders. Fifty-four patients had been treated with lithium salts for more than 6 months.

After a complete description of the study was given to the subjects, written informed consent was obtained.

Information about the recurrence of illness was collected following the best-estimation procedure, taking into account available charts, case notes, and information provided by at least one relative [28]. Recurrence rates of episodes were evaluated by considering the episodes of illness occurring over the years from the onset of illness to the interview (recurrence rate $=$ number of episodes/duration of illness in years).

DNA was extracted from whole blood by manual extraction, using the Illustra Blood Genomic Prep Midi Flow Kit (GE Healthcare, Milan, Italy). To identify the polymorphism $S L C 1 A 2-181 \mathrm{~A}>\mathrm{C}$ T/G alleles (DNA forward strand), a standard polymerase chain reaction (PCR) was carried with the following primers: $5^{\prime}$ - GCC ACC TGT GCT TTG CTG $-3^{\prime}$ and 5'- TGA TGT CAG CTC TCG ACG AA - $3^{\prime}$. The PCR was carried out in a $10 \mu \mathrm{L}$ volume containing $150 \mathrm{ng}$ of genomic DNA, $1 \mu \mathrm{L}$ of $1 \times$ Hot Master Taq Buffer with $\mathrm{Mg}^{++}$(Eppendorf), $0.1 \mu \mathrm{L}$ of each primer [50 $\mu \mathrm{M}$ ], $1 \mu \mathrm{L}$ of deaza-dNTPs [10 mM], $0.5 \mu \mathrm{L}$ of dimethyl sulfoxide (DMSO) solution (Sigma-Aldrich, Milan, Italy), and $0.1 \mu \mathrm{L}$ of Hot Master Taq [5U/ $\mu \mathrm{L}$ ] (Eppendorf). After an initial step of $5 \mathrm{~min}$ at $94^{\circ} \mathrm{C}, 35$ cycles of amplification $\left(35 \mathrm{~s}\right.$ at $94{ }^{\circ} \mathrm{C}, 35 \mathrm{~s}$ at $58{ }^{\circ} \mathrm{C}, 45 \mathrm{~s}$ at $70{ }^{\circ} \mathrm{C}$ ) and a final extension step of $10 \mathrm{~min}$ at $70{ }^{\circ} \mathrm{C}$ were performed. An aliquot of PCR product was digested using Msp I [20U/ $\mu \mathrm{L}$ ] (New England Biolabs, England, UK) and incubated at $37^{\circ} \mathrm{C}$ for $8 \mathrm{~h}$; fragments were separated in agarose gels. Depending on the presence of two or three restriction Msp I sites, either three fragments (allele $\mathrm{T}$ ) or four fragments (allele $\mathrm{G}$ ) were produced.

Data were analyzed within the context of the general linear model [29, 30]. Total episode recurrence rates were the dependent variable, SLC1A2 - 181A $>$ C genotype was the main factor, and gender, age at onset, total number of episodes, and duration (number of months) of lithium treatment were considered as nuisance covariates. The significance of the effect of the single independent factors on the dependent variable was estimated (least squares method) by parametric estimates of predictor variables and following standard computational procedures [31].

In a second analysis we investigated the interaction between SLC1A2 -181A $>\mathrm{C}$ and lithium treatment, considering lithium-treated patients to be those taking lithium for more than 6 months. Again, total episode recurrence rates were the dependent variable, SLC1A2 $-181 \mathrm{~A}>\mathrm{C}$ genotype and lithium were the main factors, and gender, age at onset, and total number of episodes were considered as nuisance covariates. Moreover, we investigated the effect of SLC1A2 -181A $>$ C separately in patients who were and patients who were not lithium treated.

Then we considered separately as dependent variables the frequency of manic and depressive episodes, maintaining the $S L C 1 A 2-181 \mathrm{~A}>\mathrm{C}$ genotype as the main factor, and gender, age at onset, total number of depressive and manic episodes, and duration of lithium treatment as nuisance covariates.

Finally we analyzed the ratio between the number of manic and depressive episodes as a dependent variable.

\section{Results}

The allelic frequencies were similar to those observed for the general population ( $\mathrm{T}=62.5 \%, \mathrm{G}=37.5 \%)$ [12]. The distribution of SLC1A2 genotypes ( $n=49$ for T/T, $n=62$ for $\mathrm{T} / \mathrm{G}, n=17$ for $\mathrm{G} / \mathrm{G}$ ) respected the Hardy-Weinberg equilibrium $\left(\chi^{2}=0.142 ; p=0.71\right)$. Clinical and demographic data are shown in Table 1 . The general linear model analysis yielded a significant effect of the whole model on total recurrence of episodes $\left(\mathrm{R}^{2}=0.476\right.$; $\mathrm{F}=11.50 ; p<0.001)$, indicating that the included factors significantly explained the recurrence of illness. The SLC1A2 - 181A $>$ C genotype significantly influenced the total recurrence of episodes (Figure 1), with T/T homozygotes showing a significantly lower frequency of episodes $(0.654 \pm 0.53$ for $\mathrm{T} / \mathrm{T}, 0.794 \pm 0.786$ for $\mathrm{T} / \mathrm{G}$, $1.018 \pm 1.014$ for $\mathrm{G} / \mathrm{G} ; \mathrm{F}=4.56 ; p=0.013 ; \eta^{2}=0.08$; power $=0.76)$. Parameter estimates showed that homozygosity for the $\mathrm{G}$ allele was associated with increased recurrence of episodes ( $\beta=0.311 ; t=2.94 ; p=0.004)$; conversely, the duration of lithium treatment was associated with a reduction in the number of episodes $(\beta=-0.188$; $t=-2.548 ; p=0.012$ ). Moreover, we found an interaction between patient gender and genotype $(\mathrm{F}=5.09 ; p=0.008$; $\beta=-0.32 ; t=-2.94 ; p=0.004)$, with the genotype effect being much greater in males than in females.

We found an interaction between genotype and lithium treatment $\left(\mathrm{F}=3.77 ; p=0.026 ; \eta^{2}=0.07\right.$; power $\left.=0.67\right)$, with a significant effect of the whole model $\left(\mathrm{R}^{2}=0.52\right.$; $\mathrm{F}=8.73 ; p<0.001)$. Indeed, when only lithium-treated patients were considered, the effect of the $S L C 1 A 2-181 \mathrm{~A}>\mathrm{C}$ genotype was not statistically significant $(\mathrm{F}=0.82 ; p=$ $0.45)$, while in lithium-untreated patients we found a significant effect of genotype on the total episode recurrence rate $(\mathrm{F}=4.05 ; p=0.022)$.

When the frequency of depressions and manias was analyzed separately, the general linear model analysis yielded a significant effect of the whole model on both the 
Table 1 Clinical and demographic characteristics of the bipolar disorder sample as a whole and divided according to SLC1A2 $-181 \mathrm{~A}>\mathrm{C}$ genotypes

\begin{tabular}{lllll}
\hline Characteristic & Total sample & \multicolumn{3}{l}{$S L C 1 A 2-181 \mathrm{~A}>$ C genotype $^{\mathrm{a}}$} \\
\cline { 3 - 5 } & & GG $(n=16)$ & GT $(n=57)$ & TT $(n=37)$ \\
\hline Age (years) & $45.72 \pm 11.33$ & $45.48 \pm 8.25$ & $47.39 \pm 11.28$ & $43.27 \pm 12.32$ \\
Gender $(n$; female/male) & $76 / 34$ & $12 / 4$ & $35 / 22$ & $29 / 8$ \\
Age at onset (years) & $30.26 \pm 9.71$ & $30.66 \pm 7.02$ & $31.12 \pm 9.95$ & $28.77 \pm 10.37$ \\
Duration of illness (years) $^{\mathrm{b}}$ & $15.45 \pm 10.30$ & $14.78 \pm 9.66$ & $16.23 \pm 10.95$ & $14.5 \pm 9.68$ \\
Number of episodes $^{\mathrm{b}}$ & $9.06 \pm 12.63$ & $9.62 \pm 11.45$ & $10.09 \pm 15.58$ & $7.24 \pm 6.76$ \\
Recurrence rate $^{\mathrm{b}, \mathrm{c}}$ & $0.77 \pm 0.75$ & $1.02 \pm 1.01$ & $0.78 \pm 0.78$ & $0.65 \pm 0.52$ \\
Mean duration of lithium treatment (months) $^{\mathrm{b}}$ & $33.44 \pm 56.18$ & $38.25 \pm 60.98$ & $37.67 \pm 61.49$ & $24.86 \pm 44.86$ \\
\hline
\end{tabular}

${ }^{a}$ According to DNA forward-strand $\mathrm{T}$ and $\mathrm{G}$ alleles

$\mathrm{b}$ The data are expressed as mean \pm standard deviation. The $t$ and $p$ values for all comparisons between genotype groups were nonsignificant

${ }^{c}$ Recurrence rate $=$ number of episodes/duration of illness in years

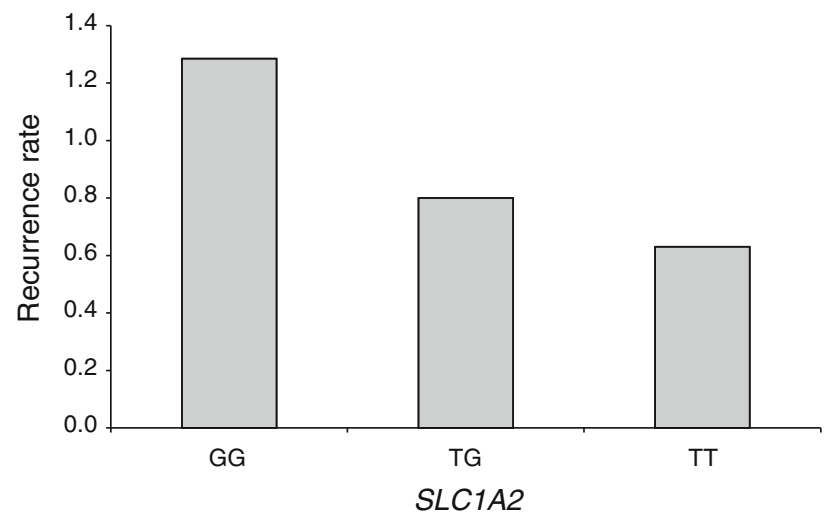

Fig. 1 Total recurrence rates of bipolar disorder episodes in different SLC1A2 $-181 \mathrm{~A}>\mathrm{C}$ genotype groups, according to DNA forwardstrand $\mathrm{T}$ and $\mathrm{G}$ alleles. Recurrence rate $=$ number of episodes/ duration of illness in years

frequency of depressive episodes $\left(\mathrm{R}^{2}=0.585 ; \mathrm{F}=17.83\right.$; $p<0.001)$ and on the frequency of manic episodes $\left(\mathrm{R}^{2}=0.196 ; \mathrm{F}=3.09 ; p=0.004\right)$. Parameter estimates showed that homozygosity for the $\mathrm{G}$ allele was significantly associated with increased recurrence of depressive episodes $(\beta=-0.26 ; t=2.81 ; p=0.006)$ and was marginally associated with manic episodes $(\beta=-0.257$; $t=1.96 ; p=0.052$ ). Moreover, we observed a difference between the genotype groups in the mania to depression ratio, with $\mathrm{G} / \mathrm{G}$ homozygotes showing a greater number of manic episodes than depressive episodes $(\mathrm{F}=3.83$; $p=0.025 ; \eta^{2}=0.07$; power $=0.69$ ).

\section{Discussion}

According to our results, the glutamatergic system could be hypothesized to have a role in the history of illness in BD.
An SLC1A2 functional polymorphism was shown to significantly influence the total episode recurrence rate, with wild-type $\mathrm{T}$ homozygotes presenting the lowest number of episodes, G homozygotes reporting the highest number, and heterozygotes showing an intermediate phenotype. When depression and mania were considered separately, even if statistical significance was lost, the same trend was observed. Since $S L C 1 A 2-181 \mathrm{~A}>\mathrm{C}$ is a functional polymorphism, with the mutant $\mathrm{G}$ allele being associated with reduced transcriptional activity, a higher recurrence rate should be considered to be linked to an increase in free glutamate levels. Moreover, we found an interaction between patient gender and genotype that influenced the recurrence rate: these data confirmed the clinical observation that the history of illness differs between male and female subjects with BD. Finally, we found that the mania recurrence rate was higher than the depression recurrence rate in $\mathrm{G}$ homozygotes. This finding is really interesting, considering the lack of studies investigating the role of the glutamatergic system in mania. However, in contrast to what has been reported in unipolar depression, Glx levels were found to be consistently elevated in both adult patients [23, 24] and pediatric patients [25] with BD. Glx levels were found to be more elevated also during euthymia [32] and during manic episodes [33], thus suggesting that patients affected by BD have higher Glx levels irrespective of the illness phase [34].

Although the pathophysiology of $\mathrm{BD}$ remains poorly understood, findings from imaging studies suggest that BD is associated with neuropathologic changes in specific brain regions, particularly within the frontal and temporal cortices and subcortical structures making up the anterior limbic network [35]. Structural studies have observed significant differences between bipolar patients and healthy 
subjects in prefrontal and frontal cortical volume [36]. Additionally, in vivo imaging and postmortem studies have revealed significant brain atrophy in BD patients, with a decrease in cortical thickness [37], as well as reduced numbers and/or sizes of glia and neurons in discrete brain areas [38].

In a recent study, decreased expression of EAAT2 was found in the prefrontal cortex of bipolar patients [10]. It could be postulated that this decreased protein level in BD may alter glutamate recycling at the synaptic cleft and contribute to reported hyperglutamatergic function [39]. Moreover, EAATs are also involved in functions other than glutamate clearance, such as attenuation of NMDA receptor function [40], which has been found to be altered in bipolar patients [39]. Since glutamate is known to be involved in the production of reactive and excitotoxic oxygen/nitrogen species, which induce oxidative stress, leading to neuronal death, the decrease in cortical thickness observed in bipolar patients could be linked to an excess of extracellular glutamate.

We confirmed the efficacy of lithium treatment in reducing the recurrence of illness in $\mathrm{BD}$, and we found an interaction between lithium treatment and genotype. Different studies have reported an interaction between lithium salts and the glutamatergic system. Lithium salts were shown to decrease Glx levels in bipolar patients [41], consistent with evidence that mood stabilizers can attenuate glutamatergic function either by promoting glutamate uptake from the synapse or by postsynaptically reducing the intracellular signaling cascade [15].

A recent report suggested that chronic lithium treatment downregulates glutamate receptor $\alpha$-amino-3-hydroxy-5methyl-4-isoxazolepropionic acid (AMPA) [GRIA2] in a human neuronal cell line [42] and causes decreased synaptic expression of glutamate receptor 2 in hippocampal neurons [43].

Lithium is hypothesized to exert complex neuroprotective or neurotrophic effects that counteract pathologic processes in the brains of patients with BD [44, 45], most importantly by increasing cellular resilience and altering synaptic plasticity and neuronal morphology [46]. Lithium administration was followed by an increase in gray matter volumes in healthy humans [47] and in patients affected by BD [48], thus possibly counteracting gray matter volume reductions in critical cortical areas involved in the cognitive and emotional disregulation experienced by the patients [49]. Pivotal prospective studies confirmed that the lithium-associated gray matter volume increase during treatment correlated with the treatment response in $\mathrm{BD}$ $[50,51]$.

These effects could be postulated to be linked to a possible interaction between lithium and glutamatergic systems. Supporting this hypothesis, our results show that lithium seems to balance the negative influence of an increase in free glutamate levels on the history of illness in $\mathrm{BD}$. Indeed, we found that while in lithium-free patients the mutant $G$ allele linked to reduced transcriptional activity was significantly associated with a higher recurrence rate, in lithium-treated patients the SLC1A2 polymorphism effect was countered.

Lithium could counteract the effect of SLC1A2 gene variants by acting on both the pre-synaptic and post-synaptic components of glutamate neurotransmission.

In vitro, lithium can inhibit NMDA receptor-mediated calcium influx [52] and has been shown to cause a reduction in the time to recovery from desensitization of AMPA receptors, resulting in the observed increase in singlechannel open probability [53]. Interestingly, inhibition of NMDA transmission associated with an increase in AMPA activity seems to be the same mechanism that has been suggested to underlie the antidepressant effect of ketamine $[21,54]$.

Glutamate transporters have been shown to be biochemically regulated, e.g., via arachidonic acid (AA) [55, 56]. Lithium could affect EAAT function via an effect on AA because, when given chronically to rats, lithium decreases AA turnover in brain phospholipids and commonly targets AA cascade kinetics as well as AA cascade enzymes and their transcription factors in the rat brain.

Finally, valproate increases levels of EAAT2 in the hippocampus [57], so a common mechanism could be hypothesized to explain the effect observed in our study; however, further studies are needed to clarify this issue.

One major limitation of this study was the lack of information regarding other psychopharmacologic treatments, besides ongoing lithium treatments, received by the patients. Recent studies have shown that treatment-emergent mania is expected in roughly $25 \%$ of bipolar patients treated with antidepressant drugs [58] and that highly complex medication regimens are often required during naturalistic outpatient treatment of BD [59]. Further prospective studies will consider drug treatments and other factors (e.g., other genes, drugs, exposure to emotional and physical stressors) to assess the potential of SLC1A2 $-181 \mathrm{~A}>\mathrm{C}$ in predicting the individual course of the illness.

Another major limitation of the study was the small sample size of male patients $(n=34)$. Considering the finding of a gene-gender interaction influencing the recurrence rate, further studies are needed to investigate this issue.

Other limitations of the study included issues such as generalizability, possible undetected past comorbidities, population stratification, no placebo control, lack of genome-wide association studies, and lack of consideration of gene-gene and gene-environment interactions. 


\section{Conclusion}

Considering the limitations of our study, and considering that the robustness and interpretation of the finding of altered glutamatergic activity in BD is still unclear, further research is needed to explore the relationship between glutamate and clinical features in BD.

Funding Disclosures None of the authors have financial disclosures that are pertinent to the content of this article. The authors' research unit received research grants from the Italian Ministry of University and Scientific Research, the Italian Ministry of Health, and the European Union (FP7 grant no. 222963).

Author Contributions Sara Dallaspezia and Francesco Benedetti designed the study. Francesco Benedetti obtained the funding for the study. Sara Dallaspezia, Sara Poletti, Cristina Colombo, and Francesco Benedetti were involved in the participants' recruitment and selection. Cristina Lorenzi and Adele Pirovano performed the genotyping. Sara Dallaspezia and Sara Poletti wrote the first draft of the manuscript, with the other authors contributing to data interpretation and final manuscript preparation. All authors take final responsibility for the decision to submit the manuscript for publication. Sara Dallaspezia, Sara Poletti, and Francesco Benedetti had full access to all of the data in the study and take responsibility for the integrity of the data and the accuracy of the data analysis.

\section{References}

1. Solomon DA, Keitner GI, Miller IW, Shea MT, Keller MB. Course of illness and maintenance treatments for patients with bipolar disorder. J Clin Psychiatry. 1995;56(1):5-13.

2. Deister A, Marneros A. Predicting the long-term outcome of affective disorders. Acta Psychiatr Scand. 1993;88(3):174-7.

3. Gitlin MJ, Swendsen J, Heller TL, Hammen C. Relapse and impairment in bipolar disorder. Am J Psychiatry. 1995;152(11): 1635-40.

4. Nivoli AM, Pacchiarotti I, Rosa AR, Popovic D, Murru A, Valenti M, et al. Gender differences in a cohort study of 604 bipolar patients: the role of predominant polarity. J Affect Disord. 2011;133(3):443-9.

5. Benedetti F, Serretti A, Pontiggia A, Bernasconi A, Lorenzi C, Colombo $\mathrm{C}$, et al. Long-term response to lithium salts in bipolar illness is influenced by the glycogen synthase kinase $3-\beta-50 \mathrm{~T} / \mathrm{C}$ SNP. Neurosci Lett. 2005;376(1):51-5.

6. Schloesser RJ, Martinowich K, Manji HK. Mood-stabilizing drugs: mechanisms of action. Trends Neurosci. 2012;35(1): 36-46.

7. Kim K, Lee SG, Kegelman TP, Su ZZ, Das SK, Dash R, et al. Role of excitatory amino acid transporter-2 (EAAT2) and glutamate in neurodegeneration: opportunities for developing novel therapeutics. J Cell Physiol. 2011;226(10):2484-93.

8. Danbolt NC. Glutamate uptake. Prog Neurobiol. 2001;65(1): $1-105$.

9. Rothstein JD, Dykes-Hoberg M, Pardo CA, Bristol LA, Jin L, Kuncl RW, et al. Knockout of glutamate transporters reveals a major role for astroglial transport in excitotoxicity and clearance of glutamate. Neuron. 1996;16(3):675-86.

10. Rao JS, Kellom M, Reese EA, Rapoport SI, Kim HW. Dysregulated glutamate and dopamine transporters in postmortem frontal cortex from bipolar and schizophrenic patients. J Affect Disord. 2012;136(1-2):63-71.

11. Meyer T, Ludolph AC, Morkel M, Hagemeier C, Speer A. Genomic organization of the human excitatory amino acid transporter gene GLT-1. Neuroreport. 1997;8(3):775-7.

12. Mallolas J, Hurtado O, Castellanos M, Blanco M, Sobrino T, Serena J, et al. A polymorphism in the EAAT2 promoter is associated with higher glutamate concentrations and higher frequency of progressing stroke. J Exp Med. 2006;203(3):711-7.

13. Pampliega O, Domercq M, Villoslada P, Sepulcre J, RodriguezAntiguedad A, Matute C. Association of an EAAT2 polymorphism with higher glutamate concentration in relapsing multiple sclerosis. J Neuroimmunol. 2008;195(1-2):194-8.

14. Matsumoto Y, Suzuki A, Ishii G, Oshino S, Otani K, Goto K. The $-181 \mathrm{~A} / \mathrm{C}$ polymorphism in the excitatory amino acid transporter-2 gene promoter affects the personality trait of reward dependence in healthy subjects. Neurosci Lett. 2007;427(2):99-102.

15. Krystal JH, Sanacora G, Blumberg H, Anand A, Charney DS, Marek G, et al. Glutamate and GABA systems as targets for novel antidepressant and mood-stabilizing treatments. Mol Psychiatry. 2002;7(Suppl. 1):S71-80.

16. Sanacora G, Gueorguieva R, Epperson CN, Wu YT, Appel M, Rothman DL, et al. Subtype-specific alterations of gamma-aminobutyric acid and glutamate in patients with major depression. Arch Gen Psychiatry. 2004;61(7):705-13.

17. Manji HK, Quiroz JA, Payne JL, Singh J, Lopes BP, Viegas JS, et al. The underlying neurobiology of bipolar disorder. World Psychiatry. 2003;2(3):136-46.

18. Hashimoto K, Sawa A, Iyo M. Increased levels of glutamate in brains from patients with mood disorders. Biol Psychiatry. 2007;62(11):1310-6.

19. Singh J, Zarate CA Jr, Krystal AD. Case report: successful riluzole augmentation therapy in treatment-resistant bipolar depression following the development of rash with lamotrigine. Psychopharmacology. 2004;173(1-2):227-8.

20. Zarate CA Jr, Quiroz JA, Singh JB, Denicoff KD, De Jesus G, Luckenbaugh DA, et al. An open-label trial of the glutamatemodulating agent riluzole in combination with lithium for the treatment of bipolar depression. Biol Psychiatry. 2005;57(4): 430-2.

21. Moghaddam B, Adams B, Verma A, Daly D. Activation of glutamatergic neurotransmission by ketamine: a novel step in the pathway from NMDA receptor blockade to dopaminergic and cognitive disruptions associated with the prefrontal cortex. J Neurosci. 1997;17(8):2921-7.

22. Machado-Vieira R, Salvadore G, Diazgranados N, Zarate CA Jr. Ketamine and the next generation of antidepressants with a rapid onset of action. Pharmacol Ther. 2009;123(2):143-50.

23. Cecil KM, DelBello MP, Morey R, Strakowski SM. Frontal lobe differences in bipolar disorder as determined by proton MR spectroscopy. Bipolar Disord. 2002;4(6):357-65.

24. Dager SR, Friedman SD, Parow A, Demopulos C, Stoll AL, Lyoo IK, et al. Brain metabolic alterations in medication-free patients with bipolar disorder. Arch Gen Psychiatry. 2004;61(5):450-8.

25. Castillo M, Kwock L, Courvoisie H, Hooper SR. Proton MR spectroscopy in children with bipolar affective disorder: preliminary observations. AJNR Am J Neuroradiol. 2000;21(5):832-8.

26. Benedetti F, Calabrese G, Bernasconi A, Cadioli M, Colombo C, Dallaspezia $\mathrm{S}$, et al. Spectroscopic correlates of antidepressant response to sleep deprivation and light therapy: a 3.0 Tesla study of bipolar depression. Psychiatry Res. 2009;173(3):238-42.

27. Dalvie S, Horn N, Nossek C, van der Merwe L, Stein DJ, Ramesar R. Psychosis and relapse in bipolar disorder are related to GRM3, DAOA, and GRIN2B genotype. Afr J Psychiatry (Johannesbg). 2010;13(4):297-301. 
28. Leckman JF, Sholomskas D, Thompson WD, Belanger A, Weissman MM. Best estimate of lifetime psychiatric diagnosis: a methodological study. Arch Gen Psychiatry. 1982;39(8):879-83.

29. McCulloch CE, Searle SR, Neuhaus JM. Generalized, linear, and mixed models. 2nd ed. New York: Wiley; 2008.

30. Kim K, Timm N. Univariate and multivariate general linear models: theory and applications with SAS. 2nd ed. New York: Chapman and Hall; 2007.

31. Hill T, Lewicki P. General linear models. In: Hill T, Lewicki P, editors. Statistics: methods and applications. A comprehensive reference for science, industry, and data mining. Tulsa: StatSoft; 2006. p. 245-76.

32. Bruhn H, Stoppe G, Staedt J, Merboldt KD, Hanicke W, Frahm J. Quantitative proton MRS in vivo shows cerebral myo-inositol and cholines to be unchanged in manic-depressive patients treated with lithium [abstract]. In: Proceedings of the Society of Magnetic Resonance in Medicine: Twelfth Annual Scientific Meeting; 1993 Aug 14-20; New York.

33. Michael N, Erfurth A, Ohrmann P, Gossling M, Arolt V, Heindel $\mathrm{W}$, et al. Acute mania is accompanied by elevated glutamate/ glutamine levels within the left dorsolateral prefrontal cortex. Psychopharmacology. 2003;168(3):344-6.

34. Yildiz-Yesiloglu A, Ankerst DP. Neurochemical alterations of the brain in bipolar disorder and their implications for pathophysiology: a systematic review of the in vivo proton magnetic resonance spectroscopy findings. Prog Neuropsychopharmacol Biol Psychiatry. 2006;30(6):969-95.

35. Strakowski SM, Delbello MP, Adler CM. The functional neuroanatomy of bipolar disorder: a review of neuroimaging findings. Mol Psychiatry. 2005;10(1):105-16.

36. McDonald C, Zanelli J, Rabe-Hesketh S, Ellison-Wright I, Sham $\mathrm{P}$, Kalidindi $\mathrm{S}$, et al. Meta-analysis of magnetic resonance imaging brain morphometry studies in bipolar disorder. Biol Psychiatry. 2004;56(6):411-7.

37. Lyoo IK, Sung YH, Dager SR, Friedman SD, Lee JY, Kim SJ, et al. Regional cerebral cortical thinning in bipolar disorder. Bipolar Disord. 2006;8(1):65-74.

38. Rajkowska G. Depression: what we can learn from postmortem studies. Neuroscientist. 2003;9(4):273-84.

39. Rao JS, Harry GJ, Rapoport SI, Kim HW. Increased excitotoxicity and neuroinflammatory markers in postmortem frontal cortex from bipolar disorder patients. Mol Psychiatry. 2010;15(4):384-92.

40. Bunch L, Erichsen MN, Jensen AA. Excitatory amino acid transporters as potential drug targets. Expert Opin Ther Targets. 2009;13(6):719-31.

41. Friedman SD, Dager SR, Parow A, Hirashima F, Demopulos C, Stoll AL, et al. Lithium and valproic acid treatment effects on brain chemistry in bipolar disorder. Biol Psychiatry. 2004;56(5): 340-8.

42. Sklar P, Smoller JW, Fan J, Ferreira MA, Perlis RH, Chambert K, et al. Whole-genome association study of bipolar disorder. Mol Psychiatry. 2008;13(6):558-69.

43. Du J, Creson TK, Wu LJ, Ren M, Gray NA, Falke C, et al. The role of hippocampal GluR1 and GluR2 receptors in manic-like behavior. J Neurosci. 2008;28(1):68-79.

44. Drevets WC, Price JL, Simpson JRJ, Todd RD, Reich T, Vannier $\mathrm{M}$, et al. Subgenual prefrontal cortex abnormalities in mood disorders. Nature. 1997;38:824-7.
45. Rajkowska G. Postmortem studies in mood disorders indicate altered numbers of neurons and glial cells. Biol Psychiatry. 2000;48(8):766-77.

46. Manji HK, Moore GJ, Chen G. Lithium at 50: have the neuroprotective effects of this unique cation been overlooked. Biol Psychiatry. 1999;46:929-40.

47. Monkul ES, Matsuo K, Nicoletti MA, Dierschke N, Hatch JP, Dalwani $\mathrm{M}$, et al. Prefrontal gray matter increases in healthy individuals after lithium treatment: a voxel-based morphometry study. Neurosci Lett. 2007;429(1):7-11.

48. Bora E, Fornito A, Yucel M, Pantelis C. Voxelwise meta-analysis of gray matter abnormalities in bipolar disorder. Biol Psychiatry. 2010;67(11):1097-105.

49. Benedetti F, Radaelli D, Poletti S, Locatelli C, Falini A, Colombo $\mathrm{C}$, et al. Opposite effects of suicidality and lithium on gray matter volumes in bipolar depression. J Affect Disord. 2011;135(1-3): 139-47.

50. Lyoo IK, Dager SR, Kim JE, Yoon SJ, Friedman SD, Dunner DL, et al. Lithium-induced gray matter volume increase as a neural correlate of treatment response in bipolar disorder: a longitudinal brain imaging study. Neuropsychopharmacology. 2010;35(8): 1743-50.

51. Moore GJ, Cortese BM, Glitz DA, Zajac-Benitez C, Quiroz JA, Uhde TW, et al. A longitudinal study of the effects of lithium treatment on prefrontal and subgenual prefrontal gray matter volume in treatment-responsive bipolar disorder patients. J Clin Psychiatry. 2009;70(5):699-705.

52. Sourial-Bassillious N, Rydelius PA, Aperia A, Aizman O. Glutamate-mediated calcium signaling: a potential target for lithium action. Neuroscience. 2009;161(4):1126-34.

53. Gebhardt C, Cull-Candy SG. Lithium acts as a potentiator of AMPAR currents in hippocampal CA1 cells by selectively increasing channel open probability. J Physiol. 2010;588(Pt 20): 3933-41.

54. Maeng S, Zarate CA Jr, Du J, Schloesser RJ, McCammon J, Chen $\mathrm{G}$, et al. Cellular mechanisms underlying the antidepressant effects of ketamine: role of alpha-amino-3-hydroxy-5-methylisoxazole-4-propionic acid receptors. Biol Psychiatry. 2008;63(4): 349-52.

55. Trotti D, Volterra A, Lehre KP, Rossi D, Gjesdal O, Racagni G, et al. Arachidonic acid inhibits a purified and reconstituted glutamate transporter directly from the water phase and not via the phospholipid membrane. J Biol Chem. 1995;270(17):9890-5.

56. Zerangue N, Arriza JL, Amara SG, Kavanaugh MP. Differential modulation of human glutamate transporter subtypes by arachidonic acid. J Biol Chem. 1995;270(12):6433-5.

57. Hassel B, Iversen EG, Gjerstad L, Tauboll E. Up-regulation of hippocampal glutamate transport during chronic treatment with sodium valproate. J Neurochem. 2001;77(5):1285-92.

58. Frye MA, Helleman G, McElroy SL, Altshuler LL, Black DO, Keck PE Jr, et al. Correlates of treatment-emergent mania associated with antidepressant treatment in bipolar depression. Am J Psychiatry. 2009;166(2):164-72.

59. Post RM, Altshuler LL, Frye MA, Suppes T, Keck PE Jr, McElroy SL, et al. Complexity of pharmacologic treatment required for sustained improvement in outpatients with bipolar disorder. J Clin Psychiatry. 2010;71(9):1176-86. quiz 1252-1253. 